\title{
The Efficacy of Combined Herbal Extracts Gel Preparation in the Prevention of Postsurgical Hypertrophic Scar Formation
}

Apirag Chuangsuwanich • Krit Jongjamfa

To view enhanced content go to www.dermtherapy-open.com

Received: April 2, 2014 / Published online: June 25, 2014

(c) The Author(s) 2014. This article is published with open access at Springerlink.com

\section{ABSTRACT}

Introduction: The objective of preventing surgical scar formation is to improve the quality of life for patients. Many medical products have been used in preventing hypertrophic scarring but an optimal treatment method has not been established yet. At the present, there are several studies demonstrating the potential of herbs in scar prevention. The purpose of this study was to evaluate the efficacy of combined herbal extracts gel (CHG) in the prevention of surgical scar formation.

Methods: All the patients who underwent bilaterally symmetric surgical procedures were selected using inclusion and exclusion criteria and were then treated with both the CHG (CHG group) and placebo gel. Each gel was applied on separate scars twice daily for 12 weeks. The scars

Electronic supplementary material The online version of this article (doi:10.1007/s13555-014-0055-0) contains supplementary material, which is available to authorized users.

A. Chuangsuwanich $(\bowtie) \cdot K$. Jongjamfa Division of Plastic Surgery, Department of Surgery, Faculty of Medicine, Siriraj Hospital, Mahidol

University, Bangkok 10700, Thailand

e-mail: apirag@gmail.com were photographed and evaluated using Patient and Observer Scar Assessment Scale (PSAS and OSAS, respectively).

Results: The CHG-treated scars showed lower median PSAS scores than the placebo group in color, stiffness, thickness, irregularity, and overall scores, with statistically significant difference at 12 weeks. For OSAS, the scars in the CHG group showed lower median scores than the placebo group in pigmentation, thickness, and overall scores at 12 weeks. The median OSAS scores in vascularity, relief, and pliability differed from placebo group and were statistically significant at 8 weeks. No side effects were observed in either group.

Conclusion: The CHG might be effective in the prevention of surgical scarring.

Keywords: Aesthetic dermatology; Combined herbal extract gel; Herbal extracts; Hypertrophic scar; Surgical scar; Silicone; Quality of life

\section{INTRODUCTION}

Hypertrophic scarring is caused by an imbalance between extracellular matrix (ECM) protein deposition and degradation [1]. There are many 
factors affecting surgical scarring such as healing of the wounds, tension, and the line of the scars. Prolonged redness and post-inflammatory pigmentation of the scar tissues cause patients to be concerned about the noticeability of scars, especially in aesthetic surgery such as lower blepharoplasty, face-lift, or breast augmentation. Apart from the use of advanced wound dressing products to accelerate wound healing, many methods are used to prevent scar formation. Pressure garments, taping, and silicone gel have been prescribed for scar prevention [2]; however, these methods have not been prescribed for the reduction or prevention of post-inflammatory hyperpigmentation, which is a common problem in patients with Fitzpatrick type IV or $\mathrm{V}$ skin [3-5]. It has previously been shown that herbal extracts have various effects in scarremodeling pathways and might have scarreduction properties [6, 7]. The combined herbal extract gel $(\mathrm{CHG})$ is a composition of Allium cepa $(12 \% \mathrm{w} / \mathrm{w})$, Centella asiatica (5\% $\mathrm{w} / \mathrm{w})$, Aloe vera $(4 \% \mathrm{w} / \mathrm{w})$, Phyllanthus emblica $(1.5 \% \mathrm{w} / \mathrm{w})$, and Tamarindus indica $(1.5 \% \mathrm{w} / \mathrm{w})$ extract. This formulation was developed as it was believed that their synergistic effects would help in the prevention of scar development $[8,9]$.

Only one randomized control study has been done to evaluate the efficacy of $\mathrm{CHG}$ in preventing surgical scarring [9]. Thus, the purpose of this study was to evaluate the efficacy of the CHG in the prevention of surgical scar formation.

\section{METHODS}

Patients aged over 18 years, who were Fitzpatrick type III or IV skin, and had under gone bilaterally symmetrical surgical procedures at Siriraj Hospital (Bangkok, Thailand) were enrolled in the study. Patients with critical illnesses (such as systemic infections or hemodynamic instability), major-acute illnesses, or chronic medical illnesses that can affect wound healing (such as bleeding disorders, transplantation, diabetes, obesity, cancer, chronic renal failure, and hematologic diseases) were excluded from the study. Pregnant patients and patients with allergic reactions to $\mathrm{CHG}$ were also excluded from the study.

All patients were briefed on the study protocol. All procedures followed were in accordance with the ethical standards of the responsible committee on human experimentation (institutional and national) and with the Helsinki Declaration of 1975, as revised in 2000 and 2008. Informed consent was obtained from all patients for being included in the study.

The CHG and placebo were prepared in identical containers. The placebo gel was a combination of water, acrylate, C10-30 alkyl acrylate crosspolymer, polysorbate 20, and fragrance, and was similar in color and consistency to that of the CHG. The containers were labeled A or B. The identity of the gels was kept blind to the evaluator (second investigator) and the patients.

One week after the sutures were removed, random cards were withdrawn for each site of the scars to indicate which containers (A or B) would be applied on the sites, CHG on one scar and placebo on another scar. Application of the gels was done twice daily, once in the morning and once in the evening.

During each follow-up visit, the scars were photographed and evaluated using Patient and Observer Scar Assessment Scale (POSAS) [10$13]$. Evaluations were done on the $2 \mathrm{nd}, 4 \mathrm{th}, 8 \mathrm{th}$, and 12th week after commencing application of the gels. The assessment consisted of the two numeric scales: the Patient Scar Assessment Scale (PSAS), which was completed by the 
patient, and the Observer Scar Assessment Scale (OSAS), which was completed by one observer $[11,14]$. The median of the total score of the POSAS was analyzed using the Wilcoxon paired signed-rank test method. A $P$ value of $<0.05$ was considered to be statistically significant. All data were analyzed with SPSS software (SPSS Inc. Released 2008. SPSS Statistics for Windows, Version 17.0. Chicago: SPSS Inc.).

\section{RESULTS}

Twenty patients with Fitzpatrick type III or IV skin, classified as beige to beige-with-brown tint skin color, were enrolled in this study; however, only 17 patients completed the follow-up period. There were 34 wounds evaluated and analyzed. The average age of the patients was 39.44 years and ranged from 18 to 64 years. Demographic data are shown in Table 1. Most of the surgical procedures in our study involved excision of nevus at both arms. The other operations were intercostal drainage of median sternotomy at the subcostal area ( 2 cases) and mandibular osteotomy at both angles of the

Table 1 Demographic data

\begin{tabular}{ll}
\hline Demographic data & $n(\%)$ \\
\hline Sex $(N=17)$ & $13(76)$ \\
Female & \\
Operation $(N=20)$ & $5(25)$ \\
Lower blepharoplasty & $6(30)$ \\
Excision (excision of mole and excision of & \\
$\quad$ lipoma) & $4(20)$ \\
Liposuction & $2(10)$ \\
Breast surgery & $3(15)$ \\
Others (ICD drainage of median sternotomy & \\
\multicolumn{2}{l}{ and mandibular osteotomy) }
\end{tabular}

$I C D$ intercostal drainage chin ( 1 case). The dimensions of the scars included in this study varied from 3 to $10 \mathrm{~cm}$.

The CHG-treated scars showed lower PSAS scores compared with the placebo group in color, stiffness, thickness, irregularity, and overall scores with statistical significance at 12 weeks' follow-up ( $P$ value $0.03,0.04,0.03$, 0.04 , and 0.02, respectively; Figs. 1,2 ). The scores in pain and itching in the CHG group did not significantly differ from the placebo group at 12 weeks $(P$ value 0.72 and 0.33 , respectively). The scars in the $\mathrm{CHG}$ group showed lower OSAS scores compared with the placebo group in pigmentation, thickness, and overall scores at 12 weeks ( $P$ value 0.04, 0.04, and 0.04 , respectively). The OSAS scores in vascularity, relief, and pliability in the $\mathrm{CHG}$ group were significantly less than those in the placebo group at 8 weeks ( $P$ value $0.03,0.04$, and 0.04, respectively). No side effects were observed in either group. The efficacy of $\mathrm{CHG}$ compared to placebo gel is demonstrated in Figs. 3 and 4.

\section{DISCUSSION}

Scarring is one factor that affects patient satisfaction with operation results. The longest period of wound healing is the maturation phase [15]. In this phase, surgical scars are hypervascularized, raised, and hard for 2-3 months after the wound has healed. The patient will also feel itching and some pain during this period. If we can reduce or shorten these signs and symptoms, the patient will benefit. Patients with Fitzpatrick type III skin or above have a greater chance of developing post-inflammatory hyperpigmentation, hypertrophic scarring, and keloids than patients with Fitzpatrick type I and II skin [3]. Many methods have been described for scar prevention, such as pressure garments, taping, 

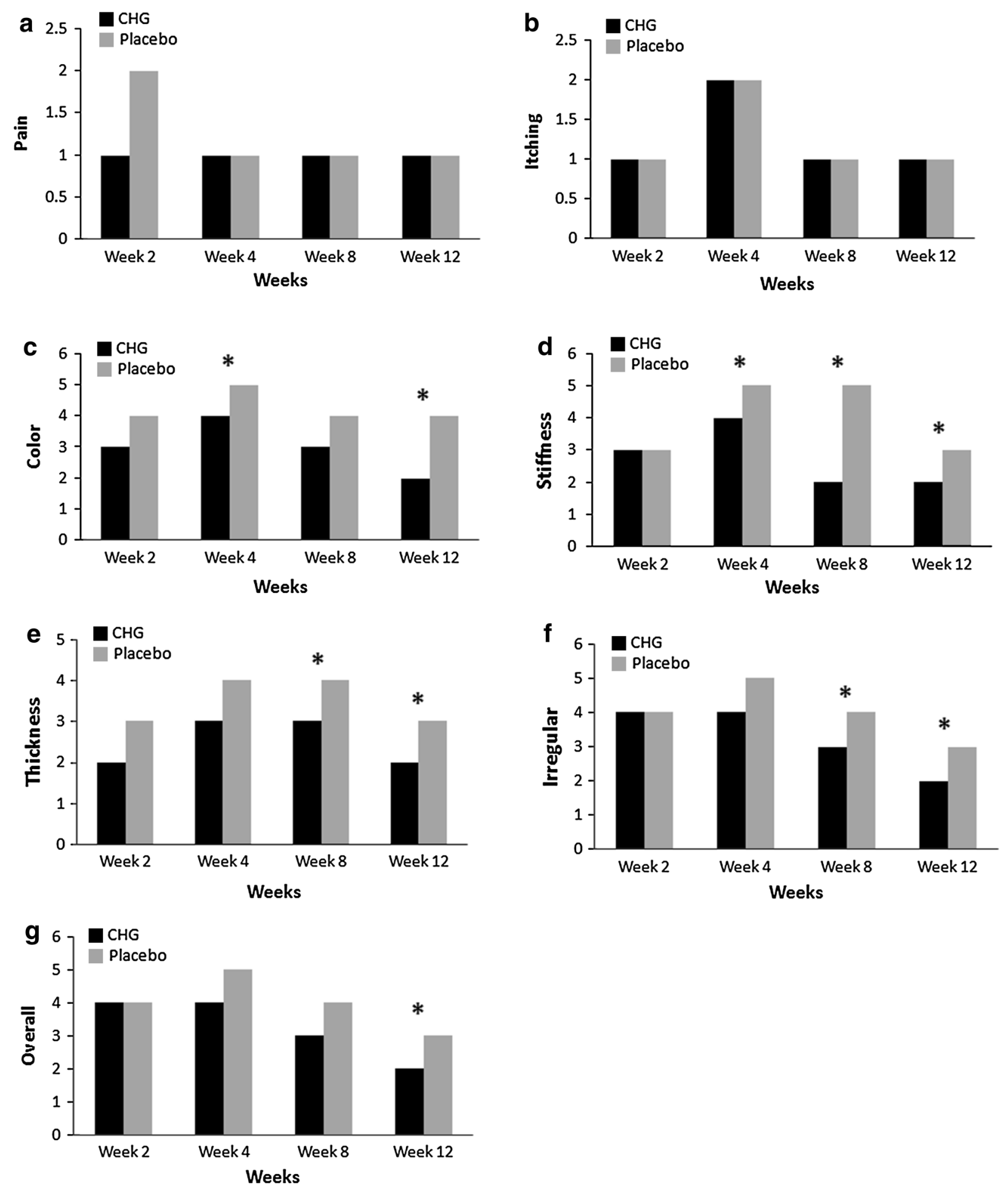

Fig. 1 Patient Scar Assessment Scale score comparison between combined herbal extracts gel (CHG) and placebo group at 2, 4, 8, and 12 weeks' follow-up 



Fig. 2 Observer Scar Assessment Scale score comparison between combined herbal extracts gel (CHG) and placebo group at $2,4,8$, and 12 weeks' follow-up 


\begin{tabular}{|c|c|c|}
\hline Treatment & 8 weeks & 12 weeks \\
\hline CHG group & & \\
\hline Placebo group & & \\
& & \\
\hline
\end{tabular}

Fig. 3 A 30-year-old female patient underwent excision nevus at both arms. At 8 weeks' follow-up, PSAS for CHG and placebo groups were 15 and 21 , respectively, and OSAS for CHG and placebo groups were 14 and 23, respectively. At 12 weeks' follow-up, PSAS for CHG and placebo groups were 12 and 19, respectively, and OSAS for CHG and placebo groups were 12 and 21, respectively. CHG combined herbal extracts gel, OSAS Observer Scar Assessment Scale, PSAS Patient Scar Assessment Scale

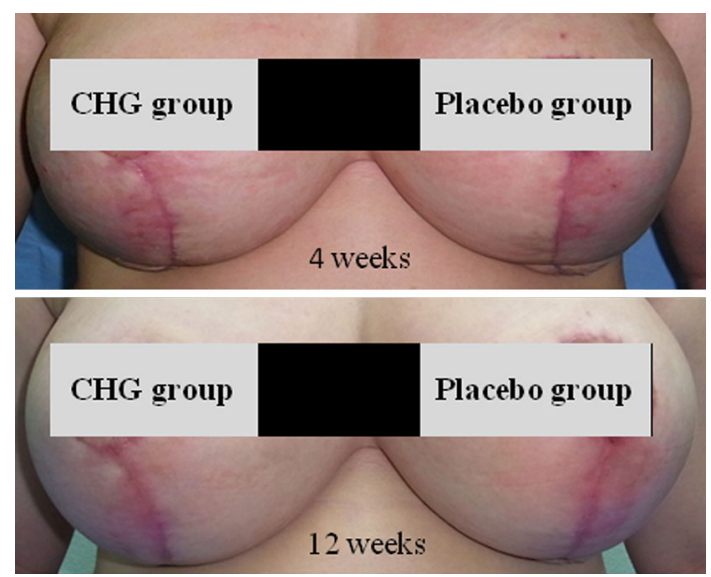

Fig. 4 A 40-year-old female patient underwent bilateral breast reduction. At 4 weeks' follow-up, PSAS scores for the CHG and placebo groups were 29 and 32, respectively, and OSAS scores for the CHG and placebo groups were 21 and 28, respectively. At 12 weeks' follow-up, PSAS scores for the CHG and placebo groups were 21 and 21, respectively, and OSAS scores for the CHG and placebo groups were 21 and 22, respectively. $C H G$ combined herbal extracts gel, OSAS Observer Scar Assessment Scale, PSAS Patient Scar Assessment Scale and silicone gel sheets/ointment [2]; however, these methods have not been described for controlling post-inflammatory hyperpigmentation and the other symptoms experienced during the maturation phase. Silicone is believed to improve scarring via wound hydration and increased static charge [16-18]. These mechanisms effectively decrease the stimulation of keratinocytes, reduce cytokine production, and inhibit excessive collagen synthesis [18]. Silicone also helps to rearrange the collagen fibers during the wound healing process via the polarization between the silicone and skin [18]. It has previously been demonstrated that silicone has benefits in scar reduction [18-21]. However, silicone gel sheets may not always be appropriate in warm climates [22]. Patients may sometimes feel sticky after silicone therapy [22]. The silicone in a gel preparation is easy to use when compared with conventional silicone gel sheeting [23]. Combination of the silicone derivative with other active compounds, such as onion extract (which have various mechanisms), may also have synergistic effects in scar prevention [6, 24].

Allium cepa (onion) extract, the main component of $\mathrm{CHG}$, is useful in reducing neoangiogenesis in hypertrophic scars and keloids, resulting in the clinical improvement of skin vascularity [7, 24-27]. It shows an anti-inflammatory effect by inhibiting lipopolysaccharide-induced tumor-necrosis factor-alpha (TNF- $\alpha$ ) production [28]. It also induces MMP-1 expression which has a key role in ECM remodeling [29]. Hosnuter et al. [24] reported that onion extract could fade scar color and the most effective therapeutic results were produced when it was combined with silicone gel sheet treatment. Several scientific reports have documented that Centella asiatica has the ability to enhance wound healing. By treating 
with Centella asiatica extract, the maturation of the scar is stimulated by the production of type I collagen. The treatment also results in a marked decrease in the inflammatory reaction and myofibroblast production [30, 31]. Asiaticoside, the active ingredient of Centella asiatica, has an anti-scarring effect by decreasing the transforming growth factor beta-1 expression and enhancing the expression of inhibitory SMAD-7 [30, 32]. Aloe vera is widely used as a traditional herbal medicine in many countries and is effective in the treatment of wounds [33]. Some studies have shown that Aloe vera extract increases the rate of healing by enhancing keratinocyte multiplication and migration, the expression of proliferationrelated factors, and epidermis formation [33, 34]. The study by Vázquez et al. [35] reported that Aloe vera could interrupt cyclooxygenase enzyme (COX) function and decrease the production of eicosanoid. Therefore, the combined extracts of Allium cepa, Centella asiatica, and Aloe vera may encourage an antiinflammatory effect. Tamarindus indica extract has alkaloid, saponin, and tannin. Alkaloid is known to assist in the epithelization of wound and chemotaxis in fibrosis [36]. Saponin significantly stimulates angiogenesis by modifying the balance of protease/protease inhibitor secretion in human endothelial vascular cells [36-38]. Phyllanthus emblica extract has antioxidant potentials as well as antimicrobial activity which can be a good therapeutic agent for accelerating the wound healing process $[39,40]$. Baek et al. [41] reported efficacy of Phyllanthus emblica in the prevention of hyperpigmentation by inhibiting tyrosinase activity. Tamarindus indica extract and Phyllanthus emblica may, therefore, have an additive effect in reducing hyperpigmentation.

In the results of our study, the color, stiffness, irregularity, and overall scores in
PSAS and pigmentation, thickness, and overall scores in OSAS of the CHG study group showed improved scores at 12 weeks. We concluded that the CHG might improve scar formation. The scars might have less chance to develop post-inflammatory hyper-pigmentation. In this study, we did not compare the CHG with any pure silicone product. Moreover, the sample size is quite small and there are many other variables that may affect the outcomes. Further studies with larger sample sizes and longer term follow-ups are needed to confirm the benefit of this product.

\section{CONCLUSION}

Combination of Herbal Extracts gel might be effective in the prevention of surgical scar formation. It has demonstrated good results, especially in improving scar appearance and scar hyperpigmentation.

\section{ACKNOWLEDGMENTS}

No funding or sponsorship was received for this study or publication of this article. All named authors meet the ICMJE criteria for authorship for this manuscript, take responsibility for the integrity of the work as a whole, and have given final approval for the version to be published.

Conflict of interest. A. Chuangsuwanich and K. Jongjamfa declare no conflict of interest.

Compliance with ethics guidelines. All patients were briefed on the study protocol. All procedures followed were in accordance with the ethical standards of the responsible committee on human experimentation (institutional and national) and with the Helsinki Declaration of 1975, as revised in 
2000 and 2008. Informed consent was obtained from all patients for being included in the study.

Open Access. This article is distributed under the terms of the Creative Commons Attribution Noncommercial License which permits any noncommercial use, distribution, and reproduction in any medium, provided the original author(s) and the source are credited.

\section{REFERENCES}

1. Gauglitz GG, Korting HC, Pavicic T, Ruzicka T, Jeschke MG. Hypertrophic scarring and keloids: pathomechanisms and current and emerging treatment strategies. Mol Med. 2011;17:113-25.

2. Juckett G, Hartman-Adams H. Management of keloids and hypertrophic scars. Am Fam Physician. 2009;80:253-60.

3. Ogawa R. The most current algorithms for the treatment and prevention of hypertrophic scars and keloids. Plast Reconstr Surg. 2010;125:557-68.

4. Chan KY, Lau CL, Adeeb SM, Somasundaram S, Nasir-Zahari MA. Randomized, placebo-controlled, double-blind, prospective clinical trial of silicone gel in prevention of hypertrophic scar development in median sternotomy wound. Plast Reconstr Surg. 2005;116:1013-20.

5. Rhee SH, Koh SH, Lee DW, Park BY, Kim YO. Aesthetic effect of silicone gel on surgical scars in Asians. J Craniofacial Surg. 2010;21:706-10.

6. Ho WS, Ying SY, Chan PC, Chan HH. Use of onion extract, heparin, allantoin gel in prevention of scarring in Chinese patients having laser removal of tattoos: a prospective randomized controlled trial. Dermatol Surg. 2006;32:891-6.

7. Draelos ZD. The ability of onion extracts gel to improve the cosmetic appearance of postsurgical scars. J Cosmet Dermatol. 2008;7:101-4.

8. Muangman P, Aramwit P, Palapinyo S, Opasanon S, Chuangsuwanich A. Efficacy of the combination of herbal extracts and a silicone derivative in the treatment of hypertrophic scar formation after burn injury. J Pharm Pharmacol. 2011;5:442-6.
9. Jenwitheesuk K, Surakunprapha P, Jenwitheesuk K, Kuptarnond C, Prathanee S, Intanoo W. Role of silicone derivative plus onion extract gel in presternal hypertrophic scar protection: a prospective randomized, double blinded, controlled trial. Int Wound J. 2012;9:397-402.

10. Vercelli S, Ferriero G, Sartorio F, Stissi V, Franchignoni F. How to assess postsurgical scars: a review of outcome measures. Disabil Rehabil. 2009;31:2055-63.

11. Van de Kar AL, Corion LUM, Smeulders MJC, Draaijers LJ, van der Horst CMaM, van Zuijlen PPM. Reliable and feasible evaluation of linear scars by the patient and observer scar assessment scale. Plast Reconstr Surg. 2005;116:514-22.

12. Bianchi F, Roccia F, Fiorini P, Berrone S. Use of Patient and Observer Scar Assessment Scale for evaluation of facial scars treated with self-drying silicone gel. J Craniofacial Surg. 2010;21:719-23.

13. Draaijers LJ, Tempelman FRH, Botman YaM, et al. The Patient and Observer Scar Assessment Scale: a reliable and feasible tool for scar evaluation. Plastic Reconstr Surg. 2004;113:1960-5.

14. POSAS The Patient and Observer Scar Assessment Scale. http://www.posas.org/downloads/english/ (Last Accessed June 9, 2014).

15. Nessen FB, Spauwen PH, Schalkwijk J, et al. On the nature of hypertrophic scars and keloid: a review. Plast Reconstr Surg. 1999;104:1435-58.

16. Atiyeh BS, Ioannovich J, Al-Amm CA, El-Musa KA, Dham R. Improving scar quality: a prospective clinical study. Aesthet Plast Surg. 2002;26:470.

17. Hirshowith B, Lindenbaum E, Har-Shai Y, Feitelberg L, Tendler M, Katz D. Static-electric field induction by a silicone cushion for the treatment of hypertrophic and keloid scars. Plast Reconstr Surg. 1998;101:1173-83.

18. Tandara AA, Mustoe TA. The role of the epidermis in the control of scarring: evidence for mechanism of action for silicone gel. J Plast Reconstr Aesthet Surg. 2008;61:1219-25.

19. Spencer JM. Case series: evaluation of a liquid silicone gel on scar appearance following excisional surgery-a pilot study. J Drugs Dermatol. 2010;9:856-8.

20. Giorgi V, Sestini S, Mannone F, et al. The use of silicone gel in the treatment of fresh surgical scars: a randomized study. Clin Exp Dermatol. 2009;34:688-93. 
21. Chuangsuwanich A, Osathalert V, Muangsombut S. Self-adhesive silicone gel sheet; a treatment for hypertrophic scars and keloids. J Med Assoc Thai. 2000;83:439-44.

22. Nikkonen MM, Pitkanen JM, Al-Qattan MM. Problems associated with the use of silicone gel sheeting for hypertrophic scars in the hot climate of Saudi Arabia. Burns. 2001;27:498-501.

23. Puri N, Talwar N. The efficacy of silicone gel for the treatment of hypertrophic scars and keloids. J Cutan Aesthet Surg. 2009;2(2):104-6.

24. Hosnuter M, Payasli C, Isikdemir A, Tekerekoglu B. The effects of onion extract on hypertrophic and keloid scars. J Wound Care. 2007;16:251-4.

25. Campanati A, Savelli A, Sandroni L, et al. Effect of allium cepa-allantoin-pentaglycan gel on skin hypertrophic scars: clinical and videocapillaroscopic results of an open-label, controlled, nonrandomized clinical trial. Dermatol Surg. 2010;36:1439-44.

26. Breu W, Dorsch W. Allium cepa L. (onion): chemistry analysis and pharmacology. In: Wager $\mathrm{H}$, Farnsworth NR, editors. Economic and medicinal plant research, vol. 6. New York: Academic Press; 1994. p. 115-47.

27. Tenni R, Zanaboni G, De Agostini MP, Rossi A, Bendotti C, Cetta G. Effect of the triterpenoid fraction of Centella asiatica on macromolecules of the connective matrix in human skin fibroblast cultures. Ital J Biochem. 1988;37:69-77.

28. Boots AW, Wilms LC, Swennen ELR, Kleinjans JCS, Bast A, Haenen GRMM. In vitro and ex vivo antiinflammatory activity of quercetin in healthy volunteers. Nutrition. 2008;24:703-10.

29. Cho JW, Cho SY, Lee SR, Lee KS. Onion extract and quercetin induce matrix metalloproteinase-1 in vitro and in vivo. Int J Mol Med. 2010;25:347-52.

30. Shuklaa A, Rasika AM, Jainb GK, Shankard R, Kulshresthac DK. In vitro and in vivo wound healing activity of asiaticoside isolated from Centella asiatica Dhawana. J Ethnopharmacol. 1999;65:1-11.

31. Ju-Lin X, Shao-Hai Q, Tian-Zeng L, et al. Effect of asiaticoside on hypertrophic scar in the rabbit ear model. J Cutan Pathol. 2009;36:234-9.
32. Tang B, Zhu B, Liang Y, et al. Asiaticoside suppresses collagen expression and TGF-b/Smad signaling through inducing Smad7 and inhibiting TGF-bRI and TGF-bRII in keloid fibroblasts. Arch Dermatol Res. 2011;303:563-72.

33. Vogler BK, Ernst E. Aloe vera: a systematic review of its clinical effectiveness. $\mathrm{Br} \mathrm{J}$ Gen Pract. 1999;49:823-8.

34. Heggers JP, Elzaim H, Garfield R, et al. Effect of the combination of Aloe vera, nitroglycerin, and L-NAME on wound healing in the rat excisional model. J Altern Complement Med. 1997;3:149-53.

35. Vázquez B, Avila G, Segura D, Escalante B. Antiinflammatory activity of extracts from Aloe vera gel. J Ethnopharmacol. 1996;55:69-75.

36. Mohamad MY, Akram HB, Bero DN. Tamarind seed extract enhances epidermal wound healing. Int $\mathrm{J}$ Biol. 2012;4:81-8.

37. Azeez S, Amudhan S, Adiga S, Rao N, Udupa LA. Wound healing profile of Area Catechu extract on different wound models in wistar rats. Kuwait Med J. 2007;39:48-52.

38. Morisaki N, Watanabe S, Tezuka $\mathrm{M}$, et al. Mechanism of angiogenic effects of saponin from ginseng Radix rubra in human umbilical vein endothelial cells. $\mathrm{Br}$ J Pharmacol. 1995;115:1188-93.

39. Datta HS, Mitra SK, Patwardhan B. Wound healing activity of topical application forms based on ayurveda. Evid Based Complement Altern Med. 2011;2011(1-10):134378.

40. Chansiripornchai P, Nimmannit U. The treatment of surgical wounds in dogs using fruit extract of amla (Phyllanthusemblica, L.). In: Proceedings of 15 th congress of FAVA-OIE joint symposium on emerging diseases, Bangkok; 2008. p. 313-4.

41. Baek YS, Ryu YB, Curtis-Long MJ, Ha TJ, Rengasamy $\mathrm{R}$, Yang MS, Park KH. Tyrosinase inhibitory effects of 1,3-diphenylpropanes from Broussonetia kazinoki. Bioorg Med Chem. 2009;17:35-41. 